\title{
Effect of drying different inclusion plasters on the mechanical properties of thermoactivated acrylic resins
}

\author{
Tarcisio José de Arruda Paes-Junior ${ }^{1}$ (D), Natália Rivoli Rossi ${ }^{1}$ (D), Tayná Mendes Inácio de Carvalho ${ }^{1}$ (D), \\ Vanessa Cruz Macedo ${ }^{1}$ (D), Michelle de Sá dos Santos Gomes ${ }^{1}$ (D), Leonardo Jiro Nomura Nakano ${ }^{1}$ (D) \\ and Cristiane Mayumi Inagati ${ }^{1 *}$ (iD)
}

\section{'Departamento de Materiais Odontológicos e Prótese, Instituto de Ciência e Tecnologia, Universidade Estadual Paulista “Júlio de Mesquita Filho"- UNESP, São José dos Campos, SP, Brasil \\ *cristianeinagati@hotmail.com}

\begin{abstract}
This article aimed to evaluate some mechanical and chemical properties of acrylic thermoactivated resins by microwave energy, varying the condition and type of plaster. The groups were divided into Lucitone and Vipi-Wave groups, with or without previous treatment (drying) of type III and IV plasters. It was evaluated flexural strength, microhardness, roughness, porosity, residual monomer, and also, time and temperature relationship of plaster and acrylic resin during the polymerization cycles. The data were analyzed using Analysis of Variance (ANOVA) 5\%, followed by Tukey's test. The results showed that the drying of the plaster influenced the results and the groups with dry plaster maintained a higher temperature permanence. Therefore, changes in the water condition contained in the inclusion plaster showed effects on the final properties of the acrylic resin, which may be a technical indicator for laboratory procedures in the manufacture of prosthetic devices.
\end{abstract}

Keywords: acrylic resin, dental plaster, flexural strength, hardness, roughness.

How to cite: Paes-Junior, T. J. A., Rossi, N. R., Carvalho, T. M. I., Macedo, V. C., Gomes, M. S. S., Nakano, L. J. N., \& Inagati, C. M. (2021). Effect of drying different inclusion plasters on the mechanical properties of thermoactivated acrylic resins. Polímeros: Ciência e Tecnologia, 31(3), e2021032. https://doi.org/10.1590/0104-1428.20210049

\section{Introduction}

Polymethylmethacrylate (PMMA) or better known as acrylic resin is a polymer widely used in Dentistry. Although there are several clinical applications of acrylic resin, from temporary crowns to total prosthesis, PMMA has some limitations, such as low mechanical resistance ${ }^{[1]}$ and dimensional change ${ }^{[2]}$. To improve these properties, several studies have been studying materials that can reinforce acrylic resin, as well as nylon, fiberglass, nanoparticles, among others ${ }^{[1,3]}$, as well as ways to improve the processing technique of acrylic resin ${ }^{[4]}$.

The mechanical properties can be influenced by the type of polymerization, for instance, by the water bath or by the autoclave ${ }^{[5,6]}$. However, according to some studies, the best technique used is microwave polymerization, which produces greater mechanical resistance and less dimensional change when compared to the heat technique, but unlikely, a lower surface hardness ${ }^{[4,7]}$. The microwave is an alternative to the conventional method being easier to handle and clean because it warms up faster. Also, the activation is homogeneous, leading to a better finish of the prostheses $^{[4,8]}$.

The dimensional change occurs during the entire process, including as a result of choosing the type of plaster used during obtaining the work ${ }^{[2]}$. Another concern is the amount of residual monomer from the polymerization which irritates

the patient's mucosa ${ }^{[9]}$. However, according to the work of Paes-Junior et al. ${ }^{[10]}$ it was possible to reduce the amount of residues by pre-drying the plaster before curing the resin. During the separation of the plaster, depending on the agent used, a smoother and brighter surface is obtained ${ }^{[1]}$. Besides, to reduce the undesirable effects of PMMA, a light- and heat-cured urethane dimethacrylate (UDMA) emerged, which is characterized by its biocompatibility, low bacterial adherence, greater resistance to masticatory loads, and thus providing greater satisfaction for the patient ${ }^{[12]}$.

Finally, the objective of the present study was to evaluate the mechanical properties of the acrylic resin by drying two types of plasters (III and IV) which were used in the inclusion phase, and also the activation method, by microwave oven or water bath. The null hypothesis was that the type and performance of dried plaster and the type of thermal activation did not influence the mechanical and chemical properties of the acrylic resin.

\section{Materials and Methods}

The materials used in the study were the following acrylic resins, Lucitone 550 (Dentsply Sirona, United States) and Vipi-Wave (Dental Vipi, Brazil) and also, the dental plasters, Gypsum stone type III Herodont (Coltene, Brazil) 
and Gypsum stone type IV Velmix (Kavo Kerr, Brazil). The groups of the present study can be seen in Table 1 .

Three types of metallic patterns of stainless steel with geometric shape of a parallelogram and dimensions respectively $2.0 \times 2.0 \times 2.0 \mathrm{~cm}, 2.0 \times 2.0 \times 1.0 \mathrm{~cm}$, and $2.0 \times 2.0 \times 0,5 \mathrm{~cm}$ were used to perform the specimens. These patterns were copied by a laboratory silicone-based impression material (Rodorsil-VWL, Brazil), and from these replicas were made in wax 7 (Classic, Brazil).

The wax replicas were included in the muffle varying the type of the plaster and its manipulation. The type III plaster was mixed in the proportion of $180 \mathrm{~g}$ of powder to $60 \mathrm{ml}$ of water. For the type IV plaster, the proportion was $180 \mathrm{~g}$ of powder to $36 \mathrm{ml}$ of water. Six wax patterns were positioned equidistantly and parallel to each other. The muffle was closed to leak the plaster into the counter muffle. The counter muffle was filled with plasters type III and IV provided in $240 \mathrm{~g}$ of powder for $80 \mathrm{ml}$ of water and $240 \mathrm{~g}$ of plaster for $50 \mathrm{ml}$ of water respectively, through the opening in the upper part of the muffle. For the groups where the plaster was previously dried, the procedure adopted was based on the methodology described by Canay et al. ${ }^{[13]}$ and adapted by Paes-Junior et al. ${ }^{[10]}$ who dried the inclusion plaster in a microwave oven for $10 \mathrm{~min}$ at $600 \mathrm{~W}$. Then, the muffles were left at room temperature for a period of one hour until completely cooled, and then with their parts open, they were stored for a minimum of 24 hours in a dry oven under temperature of $37^{\circ} \mathrm{C}$, before pressing and polymerizing acrylic resins. After one hour, the muffle parts were opened and the wax patterns were removed under immersion in heated water. Then, a thin layer of insulator for acrylic resin Al-Cote (Dentsply, Brazil) was applied with a brush over the entire surface area of the plaster. For the pressing procedure, Lucitone 550 or Vipi-Wave acrylic resin was used, being accommodated during the plastic phase in the spaces left by the wax.

Then, the muffle was closed and placed in a hydraulic press (Techno Máquinas, Brazil), until the final pressure of $1000 \mathrm{Kgf}$ maintained for 30 minutes before polymerization. For the microwave polymerization cycle was used a Continental AW-30 oven (BS Continental da Amazônia Ind. e Com. Ltda, Brazil) with a rotating plate and frequency of 2450 megahertz $(\mathrm{MHz})$ with maximum power of $900 \mathrm{~W}$. The utilized cycle was $20 \%$ of the power of the device for 20 minutes plus $5 \mathrm{~min}$ to $60 \%$ of the power. Then, the muffle was kept for about two hours at room temperature until cooled. To finish the pieces, a rotary sander (Panambra, Brazil) was used under constant refrigeration, and the wear was performed by the aluminum oxide sandpaper Norton (Norton), with decreasing weight (180, 320, 600\#).

\subsection{Fabrication of specimens for flexural strength and FTIR}

Metallic patterns made in bars shape, rectangular, with sharp edges, in the dimensions of $27 \times 12.60 \times 3.10 \mathrm{~mm}$ were included in the muffle as described before. The only difference was the use of the Zetalabor silicone (Zermack, Brazil) which was applied around the metallic patterns. After 30 minutes, the counter muffle was settled and the plaster was poured. One hour after the final inclusion phase, the muffle was opened and the metallic patterns were removed. A thin layer of insulator was applied over the silicone and the acrylic resin was included in the muffle. After its polymerization, the specimens were removed from the muffle and placed in a water container, then the finishing was performed as already described. The FT-IR was performed in a PerkinElmer Spectrum One spectrophotometer, using the attenuated total reflectance (ATR) technique, in the 500$2000 \mathrm{~cm}^{-1}$ region, with a resolution of $4 \mathrm{~cm}^{-1}$ and 16 scans, in which are obtained the quantified MR performing the respective scans per specimen. The spectra obtained were sent to a software for graph analysis (Origin 7.0 with PeakFitting), where they were imported, analyzed, plotted and the comparative graphs established $\mathrm{d}^{[14,15]}$.

\subsection{Microhardness analysis}

Before the test, each group was stored in distilled water at a temperature of $37^{\circ} \mathrm{C}+2^{\circ} \mathrm{C}$, for a period of $48 \mathrm{~h}+2 \mathrm{~h}$. After this period, the microhardness analysis was performed by Vickers indentation test (VHN), using a microdurometer (FM 700, Japan), with a load of 10gf for 5 seconds, with 3 indentations in each specimen.

\subsection{Porosity analysis}

The results were obtained through the visual inspection by three previously calibrated observers who made a ranking and assigned scores based on the following criteria: 0 (without porosity), 1 (minimum amount of porosity), 2 (average amount of porosity), and 3 (large amount of porosity). After the evaluation, the arithmetic means of the scores attributed individually by the examiners were obtained.

\subsection{Roughness analysis}

The roughness analysis was performed over one of the faces of the specimen. However, before the analysis, the samples were ultrasonically cleaned with distilled water

Table 1. Groups analyzed according to the treatment of choice.

\begin{tabular}{cc}
\hline Groups & Treatment \\
\hline LP & Lucitone 550 acrylic resin, microwave polymerization without prior treatment of type III plaster. \\
LPS & Lucitone 550 acrylic resin, microwave polymerization with pre-treatment of type III plaster (dissected plaster). \\
VP & Vipi-Wave acrylic resin, microwave polymerization without prior treatment of type III plaster. \\
VPS & Vipi-Wave acrylic resin, microwave polymerization with pre-treatment of type III plaster (dissected plaster). \\
L4 & Lucitone 550 acrylic resin, microwave polymerization without previous treatment of type IV plaster. \\
L4S & Lucitone 550 acrylic resin, microwave polymerization with previous treatment of type IV plaster (dissected plaster). \\
V4 & Vipi-Wave acrylic resin, microwave polymerization without prior treatment of type IV plaster. \\
V4S & Vipi-Wave acrylic resin, microwave polymerization with pre-treatment of type IV plaster (dissected plaster). \\
\hline
\end{tabular}


for 380 s, and dried with an air jet, free of water and oil. For the roughness test, the specimens were analyzed in a contact roughness (Mitutoyo SJ - 400), with 3 readings of $4 \mathrm{~mm}$, in two directions perpendicular to the sample surface. Roughness analysis was performed on one of the faces of the cubes used in the porosity analysis on one of the faces.

\subsection{Flexural strength analysis}

The samples were placed in distilled water and kept at a temperature of $37^{\circ} \mathrm{C}+2^{\circ} \mathrm{C}$, for a period of $48 \mathrm{~h}+2 \mathrm{~h}$. After this period, the three-point flexural test was performed by a universal testing machine - EMIC (Model DL-1000, Brazil), with a load cell of $100 \mathrm{Kgf}$ and an application speed of $5 \mathrm{~mm} / \mathrm{min}$. The flexural strength values for the groups were obtained in mega Pascals (MPa) and subjected to statistical analysis.

\subsection{Measurement of temperature in the polymerization cycle}

A muffle from each group was subjected to the analysis of the temperature gradient. For this purpose, a device in the form of a metallic tablet was inserted into one of the thickest specimens $\left(8 \mathrm{~cm}^{3}\right)$, surrounded by a plastic for its protection. According to the study by Savirmath and Mishra $^{[16]}$, dimensional change occurs with temperature change. These were positioned during the resin inclusion phase. The temperature monitoring was done 20 times, minute by minute of phase 1 of the polymerization cycle and, five times of phase 2 of the cycle.

An iButton DS1922E temperature sensor (Maxim integrated, USA) was used to perform the temperature measurement, which is a resistant and self-sufficient system that measures temperatures between $15^{\circ} \mathrm{C}$ and $140^{\circ} \mathrm{C}$. This sensor is configured to communicate with a computer using the 1-Wire serial protocol, which connects to a USB port. The sensor is connected to this device which can program and activate according to the registration data, then the results are transferred to a computer in graphs and tables. This analysis was qualitative and determined a time/temperature graph for each group.

\subsection{Remaining residual monomer (RM) analysis}

The acrylic resin samples used in the flexural test were used. The specimens were submitted to finishing with 600 grit sandpaper and, five of each group had the MR quantified, through FT-Raman spectroscopy, with the respective scans per specimen. The obtained spectra were sent to a software (Origin 7.0 with Peak Fitting) which graphs were imported, analyzed, and established.

\subsection{Statistical analysis}

The obtained values were subjected to the normality and homogeneity test. For flexural strength, microhardness, and surface roughness, it was performed the ANOVA variance analysis with the Turkey test with a significance level of $5 \%$. The porosity analysis did not follow a normal distribution so the non-parametric Kruskal-Wallis test was performed.

\section{Results and Discussions}

\subsection{Porosity analysis}

Regardless of the plaster, the type of resin, and drying (volume of $2 \mathrm{~cm}^{3}$ ), the amount of porosity was practically non-existent for all groups. For the drying (volume of $4 \mathrm{~cm}^{3}$ ), it was found slightly higher values for the LC and L4S groups. While for the drying (volume of $8 \mathrm{~cm}^{3}$ ), the LC, LCS, and VCS groups had higher porosity than the other groups (Table 2). The groups that used Vipi-Wave resin had lower porosity values, being that the VP group showed absence of porosities regardless of the specimen volume. The VC and VPS groups showed minimal bubbles for the $8 \mathrm{~cm}^{3}$ volume and absence for the other volumes. This group was in the opposite direction to the others, where plaster drying, especially for specimens of greater volume, increased the occurrence of bubbles, which may perhaps be explained by the characteristics of the type III alpha hemidrate plaster used in this group, however there was no statistical difference between drying and the type of plaster.

\subsection{Microhardness analysis}

Despite dried processo, the groups that used type IV plaster showed lower values of microhardness compared to type III plaster. Regarding resin, Lucitone presented higher microhardness values (Table 3 ).

\subsection{Roughness analysis}

Type III plaster showed the lowest roughness, and when the plaster was previously dried, it also found small roughness values (Table 4), with the Lucitone resin showing lower values (Table 5).

\subsection{Flexural strength analysis}

Lucitone 550 resin presented greater flexural strength than Vipi- Wave resin and the drying of the plaster also influenced the increase of its resistance (Table 6).

Table 2. Kruskal-Wallis for the groups and volumes observed.

\begin{tabular}{|c|c|c|c|c|c|c|c|c|c|c|c|c|}
\hline Volume & LC & $\mathrm{LCS}$ & LP & LPS & $\mathrm{VC}$ & VCS & VP & VPS & L4 & L4S & $\mathrm{V4}$ & V4S \\
\hline $2 \mathrm{~mm}$ & 1 & 1 & 0 & 0 & 0 & 0 & 0 & 0 & 0 & 1 & 0 & 0 \\
\hline $4 \mathrm{~mm}$ & 2 & 1 & 0 & 1 & 0 & 1 & 0 & 0 & 1 & 2 & 1 & 0 \\
\hline $8 \mathrm{~mm}$ & 3 & 3 & 2 & 2 & 1 & 3 & 0 & 1 & 3 & 2 & 2 & 2 \\
\hline
\end{tabular}

LC: Lucitone, without prior treatment of type II plaster. LCS: Lucitone, with pre-treatment of type II plaster. LP: Lucitone, without prior treatment of type III plaster. LPS: Lucitone, with pre-treatment of type III plaster. VC: Vipi-Wave, without prior treatment of type II plaster. VCS: Vipi-Wave, with pre-treatment of type II plaster. VP: Vipi-Wave, without prior treatment of type III plaster. VPS: Vipi-Wave, with pre-treatment of type III plaster. L4: Lucitone, without prior treatment of type IV plaster. L4S: Lucitone, with pre-treatment of type IV plaster. V4: Vipi-Wave, without prior treatment of type IV plaster. V4S: Vipi-Wave, with pre-treatment of type IV plaster. 
Table 3. Vickers microhardness averages, considering only the type of plaster.

\begin{tabular}{ccccccc}
\hline Plaster & Hardness & & Resin & Hardness & \\
\hline Type IV & $24.82 \pm 2.93$ & & A & Vipiwave & $25.85 \pm 3.14$ & A \\
Type III & $27.49 \pm 4.11$ & B & & Lucitone & $27.74 \pm 4.09$ & \\
\hline
\end{tabular}

Table 4. Roughness averages (Ra), considering only the type of plaster.

\begin{tabular}{|c|c|c|c|c|c|c|c|}
\hline Plaster & Roughness (Ra) & & & Drying & Roughness (Ra) & & \\
\hline Type III & $0.14 \pm 0.03$ & & $\mathrm{~B}$ & Yes & $0.15 \pm 0.03$ & $\mathrm{~A}$ & \\
\hline Type IV & $0.16 \pm 0.03$ & A & & No & $0.16 \pm 0.04$ & & B \\
\hline
\end{tabular}

Table 5. Average roughness of the type of resin and whether or not drying was performed.

\begin{tabular}{ccccc}
\hline Drying & Resin & & & B \\
\hline Yes & Lucitone & $0.14 \pm 0.03$ & A & \\
Yes & Vipiwave & $0.16 \pm 0.02$ & A & \\
No & Vipiwave & $0.16 \pm 0.04$ & A & \\
No & Lucitone & $0.16 \pm 0.04$ & \\
\hline
\end{tabular}

Table 6. Flexural strength averages in MPa of the types of resin.

\begin{tabular}{|c|c|c|c|c|c|c|c|}
\hline Resin & Strength & & & Drying & Strength & & \\
\hline Vipi-Wave & $102.80 \pm 15.33$ & A & & No & $107.55 \pm 17.50$ & $\mathrm{~A}$ & \\
\hline Lucitone & $121.16 \pm 31.06$ & & B & Yes & $116.41 \pm 32.02$ & & B \\
\hline
\end{tabular}

\subsection{FTIR spectroscopy analysis}

The FTIR curves of the Vipi- Wave and Lucitone resins can be interpreted in Figure 1 and 2, respectively, where it was observed that all the graphics obtained, regardless of the group, were coherent and were in the same observation ranges. In Figure 1, the curve corresponding to the band at $1150^{-1 \mathrm{~cm}}$ was related to vibration and it was possible to infer that the VP group had a lower conversion when compared to the other groups. While in Figure 2 in the $750^{-1 \mathrm{~cm}}$ band, the L4 and L4S groups had lower values.

\subsection{Temperature gradient}

Table 7 shows that for all groups there was a fast temperature rise of the resin when activated in the microwave, maintaining the temperature at the maximum peak, and decreasing quickly. When the plaster was dried, all the groups had a significant increase in the maintenance temperature, except for the LC group.

\subsection{Discussion}

The type of plaster, plaster drying method, and type of activation influenced the mechanical and chemical properties of the acrylic resin so the null hypothesis was rejected. Type III and IV plaster differ from each other in terms of the amount of water needed for their handling, so their mechanical strength was also different. In the present work, the plaster drying method was effective as it promoted a better removal of the water, without interfering with the subsequent inclusion and polymerization processes, in agreement with the works of Canay et al. ${ }^{[13]}$. This study evaluated the effect of the drying method of a type III plaster in a microwave and a conventional activation, which obtained an increase in resistance when the drying method was performed, however, there was no difference between the activation method of choice. In contrast, Paes-

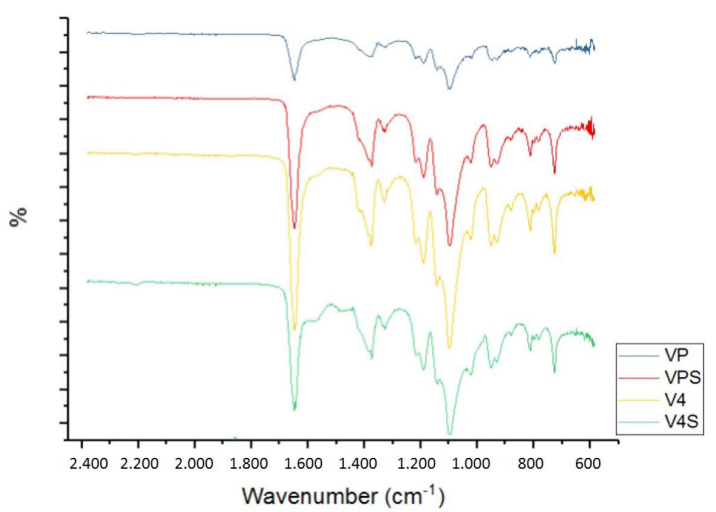

Figure 1. FTIR curve for the Vipi-Wave group.

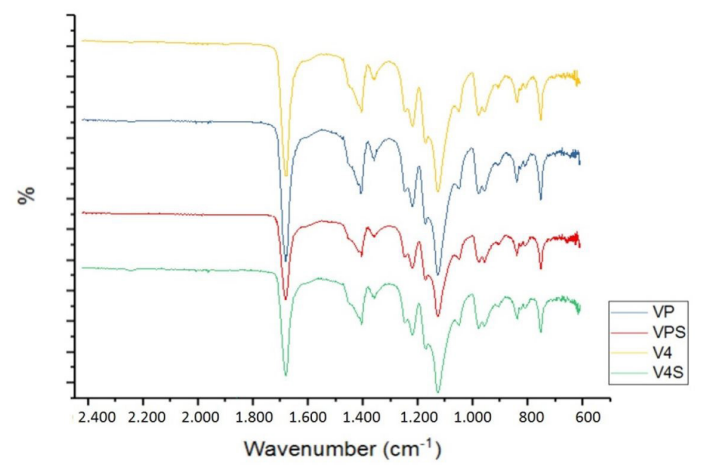

Figure 2. FTIR curve for the Lucitone group.

Junior et al ${ }^{[10]}$ analyzed whether the performance of drying plaster previously would influence the amount of residual monomer and the study found that the specimens where the 
Table 7. Maximum temperature data $\left({ }^{\circ} \mathrm{C}\right)$ for the cycles and time of permanence for the experimental groups.

\begin{tabular}{ccccccccc}
\hline Temperature $\left({ }^{\circ} \mathbf{C}\right)$ & LC & LCS & LP & LPS & VC & VCS & VP & VPS \\
\hline Temperatura peak & $123^{\circ} \mathrm{C}$ & $126^{\circ} \mathrm{C}$ & $126^{\circ} \mathrm{C}$ & $126^{\circ} \mathrm{C}$ & $120^{\circ} \mathrm{C}$ & $126^{\circ} \mathrm{C}$ & $126^{\circ} \mathrm{C}$ & $126^{\circ} \mathrm{C}$ \\
Permanence time & $30 \mathrm{~s}$ & $30 \mathrm{~s}$ & $150 \mathrm{~s}$ & $300 \mathrm{~s}$ & $30 \mathrm{~s}$ & $300 \mathrm{~s}$ & $90 \mathrm{~s}$ & $360 \mathrm{~s}$ \\
\hline
\end{tabular}

LC: Lucitone, without prior treatment of type II plaster. LCS: Lucitone, with pre-treatment of type II plaster. LP: Lucitone, without prior treatment of type III plaster. LPS: Lucitone, with pre-treatment of type III plaster. VC: Vipi-Wave, without prior treatment of type II plaster. VCS: Vipi-Wave, with pre-treatment of type II plaster. VP: Vipi-Wave, without prior treatment of type III plaster. VPS: Vipi-Wave, with pre-treatment of type III plaster.

drying method was performed obtained a lower amount of residual monomer.

The samples that had a thickness of $8 \mathrm{~cm}^{3}$ showed a significant difference in porosity when compared to the volumes of $2 \mathrm{~cm}^{3}$ and $4 \mathrm{~cm}^{3}$, regardless of the plaster choice and drying. This probably occurred, because heat dissipation is harder on thick specimens thus causing internal porosities, also found in the work of Kimpara et al. ${ }^{[17]}$ who evaluated four different polymerization cycles and found that performing short cycles has a greater amount of porosity. While Neisser et al. ${ }^{[18]}$ also studied four different polymerization cycles and observed that the shorter cycles with lower energy, raised the temperature, thus causing a higher index of porosity.

The Ibutton wireless device showed a fast increase of temperature, with a constant temperature peak of the specimens for all groups, especially in the groups where plaster was dried due to the slow heat dissipation. Regarding the FTIR test to evaluate the degree of polymerization, a qualitative aspect was considered where all the obtained graphs, regardless of the group, had the same observation ranges.

In the analysis of roughness, the LPS group showed a higher level of roughness, regardless of the volume of the material used. In the study performed by Rizzatti-Barbosa and Ribeiro-Dasilva ${ }^{[19]}$, it was compared the roughness of the simultaneous polymerization or double vial of the upper and lower total dentures that were made using the microwave or conventional technique. It was observed that there were no differences between the groups studied.

For the polymerization of acrylic resin, it is necessary to activate free radicals, this can occur through microwave waves, heat by hot water, or even by photoactivation. In the literature, the use of the microwave technique for polymerization reduced the amount of residual monomer present in total dentures ${ }^{[20]}$. In the present study, a significant change was observed in the flexural strength for the drying method performed in the plaster, when compared to the conventional cycle in a heated water bath, in agreement with the research by Silva et al. ${ }^{[7]}$. This study evaluated the flexural strength of four heat cycles by microwave energy and the authors concluded that when the microwave was used, the flexural strength was greater when compared to the other groups.

\section{Conclusions}

Within the limitations of this study, it was possible to conclude that the drying process of the plaster, regardless of the type of plaster used, could influence the mechanical properties of the thermoactivated resins presented in this study.

\section{Acknowledgements}

The authors would like to thank FAPESP Process $n^{\circ}$ 2014/08408-1 for their assistance in this research.

\section{References}

1. Al-Harbi, F. A., Abdel-Halim, M. S., Gad, M. M., Fouda, S. M., Baba, N. Z., AlRumaih, H. S., \& Akhtar, S. (2019). Effect of nanodiamond addition on flexural strength, impact strength, and surface roughness of PMMA denture base. Journal of Prosthodontics, 28(1), e417-e425. http://dx.doi.org/10.1111/ jopr.12969. PMid:30353608.

2. Baydas, S., Bayindir, F., \& Akyil, M. S. (2003). Effect of processing variables (Different Compression Packing Processes and Investment Material Types) and time on the dimensional accuracy of polymethyl methacrylate denture bases. Dental Materials Journal, 22(2), 206-213. http://dx.doi.org/10.4012/ dmj.22.206. PMid:12873123.

3. Karci, M., Demir, N., \& Yazman, S. (2019). Evaluation of Flexural Strength of Different Denture Base Materials Reinforced with Different Nanoparticles. Journal of Prosthodontics, 28(5), 572-579. http://dx.doi.org/10.1111/jopr.12974. PMid:30298558.

4. Durkan, R., \& Oyar, P. (2018). Comparison of mechanical and dynamic mechanical behaviors of different dental resins polymerized by different polymerization techniques. Nigerian Journal of Clinical Practice, 21(9), 1144-1149. http://dx.doi. org/10.4103/njcp.njcp_423_17. PMid:30156199.

5. Gad, M. M., Fouda, S. M., ArRejaie, A. S., \& Al-Thobity, A. M. (2019). Comparative Effect of Different Polymerization Techniques on the Flexural and Surface Properties of Acrylic Denture Bases. Journal of Prosthodontics, 28(4), 458-465. http://dx.doi.org/10.1111/jopr.12605. PMid:28543925.

6. Bural, C., Aktaş, E., Deniz, G., Ünlüçerçi, Y., Kızılcan, N., \& Bayraktar, G. (2011). Effect of post-polymerization heattreatments on degree of conversion, leaching residual MMA and in vitro cytotoxicity of autopolymerizing acrylic repair resin. Dental Materials, 27(11), 1135-1143. http://dx.doi. org/10.1016/j.dental.2011.08.007. PMid:21920593.

7. Silva, L. H., Tango, R. N., Kimpara, E. T., Saavedra, G. S. F. A., \& Paes-Junior, T. J. A. (2011). Flexural strength and microhardness of a chemically activated acrylic resin after microwave energy treatment. Revista Gauch a de Odontologia, 59(2), 237-242.

8. Figuerôa, R. M. S., Conterno, B., Arrais, C. A. G., Sugio, C. Y. C., Urban, V. M., \& Neppelenbroek, K. H. (2018). Porosity, water sorption and solubility of denture base acrylic resins polymerized conventionally or in microwave. Journal of Applied Oral Science, 26(0), e20170383. http://dx.doi. org/10.1590/1678-7757-2017-0383. PMid:29742260.

9. Melilli, D., Curró, G., Perna, A. M., \& Cassaro, A. (2009). Cytotoxicity of four types of resins used for removable denture bases: in vitro comparative analysis. Minerva Stomatologica, 58(9), 425-434. PMid:19893467.

10. Paes-Junior, T. J. A., Carvalho, R. F., Cavalcanti, S. C. M., Saavedra, G. S. F. A., \& Borges, A. L. S. (2013). Influence 
of plaster drying on the amount of residual monomer in heatcured acrylic resins. Brazilian Journal of Oral Sciences, 12(2), 84-89. http://dx.doi.org/10.1590/S1677-32252013000200003.

11. Kim, T. H., Ahn, T. J., Enciso, R., \& Knezevic, A. (2014). Effect of gypsum separating media on the appearance of stone cast surfaces. The Journal of Prosthetic Dentistry, 112(4), 1001-1005. http://dx.doi.org/10.1016/j.prosdent.2014.06.011. PMid:25134996.

12. Ali, I. L., Yunus, N., \& Abu-Hassan, M. I. (2008). Hardness, flexural strength, and flexural modulus comparisons of three differently cured denture base systems. Journal of Prosthodontics, 17(7), 545-549. http://dx.doi.org/10.1111/j.1532849X.2008.00357.x. PMid:18761582.

13. Canay, S., Hersek, N., Çiftçi, Y., \& Akça, K. (1999). Comparision of diametral tensile strength of microwave and oven-dried investment materials. The Journal of Prosthetic Dentistry, 82(3), 286-290. http://dx.doi.org/10.1016/S0022-3913(99)70082-X. PMid:10479254.

14. Rodriguez, L. S., Paleari, A. G., Giro, G., Oliveira, N. M., Jr., Pero, A. C., \& Compagnoni, M. A. (2013). Chemical characterization and flexural strength of a denture base acrylic resin with Monomer 2-Tert-Butylaminoethyl Methacrylate. Journal of Prosthodontics, 22(4), 292-297. http://dx.doi. org/10.1111/j.1532-849X.2012.00942.x. PMid:23106690.

15. Türkcan, I., Nalbant, A. D., Bat, E., \& Akca, G. (2018). Examination of 2-methacryloyloxyethyl phosphorylcholine polymer coated acrylic resin denture base material: surface characteristics and candida albicans adhesion. Journal of Materials Science. Materials in Medicine, 29(7), 107. http:// dx.doi.org/10.1007/s10856-018-6116-7. PMid:29971499.
16. Savirmath, A., \& Mishra, V. (2016). A comparative evaluation of the linear dimensional changes of two different commercially available heat cure acrylic resins during three different cooling regimens. Journal of Clinical and Diagnostic Research : JCDR, 10(11), 50-54. http://dx.doi.org/10.7860/JCDR/2016/22066.8903. PMid:28050504.

17. Kimpara, E. T., Silva, L. H., Costa, C. B., Borges, A. L. S., Tango, R. N., \& Paes-Junior, T. J. A. (2009). Acrylic resin for complete denture: effect of polymerization cycles at residual monomer released and porosity evidence. Revista da Faculdade de Odontologia: UPF, 14(1), 37-41.

18. Neisser, M. P., Hilgert, E., Cavalcanti, B. N., Barros, E. A., \& Magalhães, O., No. (2005). Thermal curves of acrylic resins in microwave curing. Brazilian Dental Science, 8(2), 25-30. http://dx.doi.org/10.14295/bds.2005.v8i2.385.

19. Rizzatti-Barbosa, C. M., \& Ribeiro-Dasilva, M. C. (2009). Influence of double flask investing and microwave heating on the superficial porosity, surface roughness, and knoop hardness of acrylic resin. Journal of Prosthodontics, 18(6), 503-506. http://dx.doi.org/10.1111/j.1532-849X.2009.00469.x. PMid: 19432756.

20. Urban, V. M., Machado, A. L., Oliveira, R. V., Vergani, C. E., Pavarina, A. C., \& Cass, Q. B. (2007). Residual monomer of reline acrylic resins: effect of water-bath and microwave postpolymerization treatments. Dental Materials, 23(3), 363-368. http://dx.doi.org/10.1016/j.dental.2006.01.021. PMid:16620950.

Received: June 21, 2021

Revised: Oct. 18, 2021

Accepted: Nov. 05, 2021 